\section{Neue Einwegmischer}

D s Unternehmen Tartler hat sein Sortiment an rotierenden Einwegmischern erweitert und bietet nun eine Auswahl von 17 verschiedenen Standardmischern an, die sich nicht nur in Durchmesser (6 bis $35 \mathrm{~mm}$ ) und Länge (50 bis $250 \mathrm{~mm}$ ) unterscheiden, sondern vor allem durch ihre Wendelgeometrie, sodass jetzt für jeden Anwendungsfall der optimale Mischer zur Verfügung steht.

Rotierende Einwegmischer bilden die Speerspitze einer Kunstharz-Dosier- und Mischanlage. Unmittelbar vor der Applikation erfolgt hier auf einer Strecke von nur wenigen Zentimetern die letzte Phase der Vermischung von Harz, Härter und weiteren Komponenten. Was dabei im Inneren des Mischers geschieht, hat maßgeblichen Einfluss auf die Qualität des polymeren Outputs und wird entscheidend mitbestimmt von der Geometrie der Mischwendel (Förderspirale).

Das neue Sortiment beinhaltet mit den Typen 22/04 und 35/04 unter anderem zwei dynamische Kunststoffmischer, die eine preiswerte Alternative $\mathrm{zu}$ teuren Stahlmischern darstellen. Neben diesen Standardmischern wurde jetzt ein Einwegmischer mit segmentierter Wendel entwickelt, der die doppelte Anzahl von Mischpunkten besitzt und bei halbierter Drehzahl eine deutlich bessere Durchmischung erzielt. Die Konstruktion dieses hocheffizienten und zugleich energiesparenden Mischers ist zum Patent angemeldet.

Weitere Infos: www.tartler.com

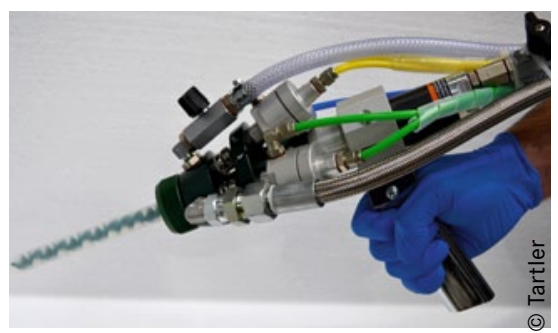

Was im Inneren rotierender Einwegmischer geschieht, hat maßgeblichen Einfluss auf die Qualität des dosierten Materials.

\title{
Weiterentwickelte Dispenserserie
}

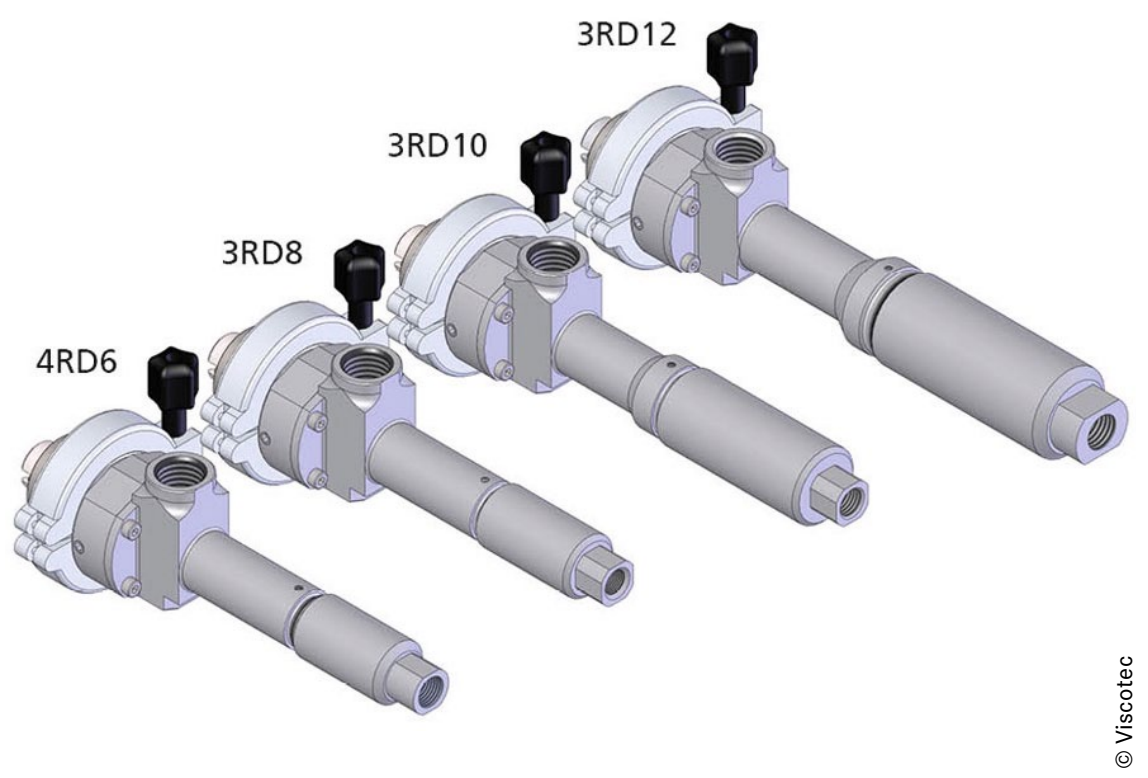

Die ventilfreie Technik dieser Dispenser eignet sich besonders für die Dosierung hochviskoser, scher- und druckempfindlicher sowie gefüllter Materialien.

$V_{\mathrm{s}}^{\mathrm{i}}$ iscoTec hat seine RD-Dispenserserie einem Facelift unterzogen. Diese Dosierpumpen basieren auf dem Exzenterschnecken-Pumpenprinzip und sind je nach Größe in der Lage, kleinste Dosiermengen im $\mu \mathrm{l}$ Bereich bis hin $\mathrm{zu}$ größeren ml-Mengen in höchster Genauigkeit $\mathrm{zu}$ dosieren.

Um nun einfachstes Handling sowie zeit- und kostensparende Instandhaltung zu gewährleisten, wurde in einer neuen Bauform das Dichtungspaket komplett im separaten Lagergehäuse integriert. Somit muss bei einer Reinigung (z. B. bei einem Produktwechsel oder der turnusmäßigen Instandhaltung) der Dichtungsbereich nicht mehr freigelegt werden.

Diese Neuerung verringert deutlich die Instandhaltungs- und Rüstzeiten der Dosiersysteme und ermöglicht häufigere Produktwechsel. Es verringert sich nicht nur der Zeitaufwand (Personalkosten, Anlagenstilstand), sondern auch der Materialaufwand der für die Reinigung benötigten
Lösungsmittel und damit ebenfalls der Entsorgungsaufwand dieser Materialien. Als Zusatznutzen ergibt sich eine längere Lebensdauer der Dichtungsteile, sodass langfristig die Instandhaltungskosten gesenkt werden können.

Die neuen RD-Dispenser besitzen die gleiche Baugröße wie die Vorgängerversionen und können durch ihre kompakte Baugröße in nahezu alle Achs- und Robotersysteme integriert oder direkt an der Dosierstation installiert werden.

Zusammen mit dem kombinierten Antriebs- und Steuerungssystem ViscoPro lassen sich diese Dosiersysteme ohne weiteren Steuerungsaufwand direkt in bestehende Anlagen integrieren. Dank ihrer ventilfreien Technik eignen sich diese Dispenser besonders für die Dosierung hochviskoser, scher- und druckempfindlicher sowie gefüllter Materialien.

Weitere Infos: ViscoTec Pumpen- u Dosiertechnik $\mathrm{GmbH}$, Töging a. Inn, mail@viscotec.de, www.viscotec.de 